\title{
TECHNOLOGY ACCEPTANCE MODEL FOR AUGMENTED REALITY AND BUILDING INFORMATION MODELING INTEGRATION IN THE CONSTRUCTION INDUSTRY
}

\author{
SUBMITTED: August 2018 \\ REVISED: August 2019 \\ PUBLISHED: March 2020 at https://www.itcon.org/2020/10 \\ EDITOR: Kumar B. \\ DOI: $10.36680 /$ j.itcon. 2020.010
}

\author{
Abdalrahman Elshafey \\ Faculty of Civil Engineering, Universiti Teknologi Malaysia, Johor Bahru, Malaysia; \\ mameabdalrahman2@live.utm.my \\ Chai Chang Saar, PhD \\ Taiwan-Malaysia CPM and Digital Technology International Centre, School of Built Environment, \\ University of Reading Malaysia, Johor Bahru, Malaysia; \\ c.s.chai@reading.edu.my \\ Eeydzah Binti Aminudin, PhD \\ Faculty of Civil Engineering, Universiti Teknologi Malaysia, Johor Bahru, Malaysia; \\ eeydzah@utm.my
}

Masoud Gheisari, PhD

Rinker School of Construction Management, University of Florida, 322 Rinker Hall, Gainesville, FL, USA; masoud@ufl.edu

\author{
Abdulrahman Usmani \\ Faculty of Civil Engineering, Universiti Teknologi Malaysia, Johor Bahru, Malaysia; \\ arch.wageeh@hotmail.com
}

SUMMARY: The digitalization of the construction industry has immense potential for dramatically improving the industry's practices. Concerning current measures in construction project management, the industry is still dependent on traditional construction methods. However, the application of fully automated techniques within the construction industry has not yet been a widespread practice. Thus, this may explain why there is a slow adaption of digital growth within the construction industry and specifically in developing countries. This study is aiming to investigate the acceptance of Building Information Modeling (BIM) and Augmented Reality (AR) integration in the construction industry. To achieve this aim, Technology Acceptance Model 3 (TAM3) was utilized. The scope was narrowed down to four developing counties (Malaysia, Egypt, Saudi Arabia, and Turkey) and a questionnaire survey was developed and distributed between construction professionals in those countries for data collection purposes. Exploratory Factor Analysis (EFA) was used to develop the TAM, and a regression analysis is used to validate it. The developed TAM3 showed that users control over BIM-AR and perception of easiness of use has the highest influence on their perception of the system usefulness, which would positively affect their intention to use the system. Additionally, unlike the findings of the original TAM3, three variables of Image, Perception of External Control, and Voluntariness illustrate new relations which can be considered as a novel outcome. The outcomes of this study can be used to evaluate the acceptance of BIM-AR Integration in the construction industry context, and the developed TAM3 can be used for the development of new BIM-AR applications in developing countries as it can predict the BIM and AR users' acceptance.

KEYWORDS: Building Information Modeling, Augmented Reality, Technology Acceptance Model (TAM), Factor Analysis, Exploratory Factor Analysis, Regression Analysis, Developing Countries.

REFERENCE: Abdalrahman Elshafey, Chai Chang Saar, Eeydzah Binti Aminudin, Masoud Gheisari, Abdulrahman Usmani (2020). Technology acceptance model for Augmented Reality and Building Information Modeling integration in the construction industry. Journal of Information Technology in Construction (ITcon), Vol. 25, pg. 161-172, DOI: 10.36680/j.itcon.2020.010

COPYRIGHT: (C) 2020 The author(s). This is an open access article distributed under the terms of the Creative Commons Attribution 4.0 International (https://creativecommons.org/licenses/by/4.0/), which permits unrestricted use, distribution, and reproduction in any medium, provided the original work is properly cited. 


\subsection{INTRODUCTION}

Technology is a critical component in the engineering sector, and current technological development has marked up the industry. It has given versatile tools to support engineering works and professions to improve the outcomes and increase industry productivity (Eastman et al., 2011; Sabongi, 2009). The construction industry has been known for being slow in adopting modern technologies and its resistibility to changes and accepting innovative ideas (Mansor, 2010). The industry is known to be information based and enormous amounts of data, drawings, specifications, and bills of quantities need to be managed and processed daily (Froese, 2005). Additionally, the construction life cycle is a big, complex and time-consuming process that contains many parallel activities. From the preliminary design stage to the demolition of the structure, too many activities are performed which leads to unwanted waste of resources, time, money, and harm to the environment (Mansor, 2010).

Building Information Modeling (BIM) is the joint effort of stakeholders in the life cycle of a facility to embed, update, extract, or adjust data in a model to bolster and reflect the role of that stakeholder. The model is a mutual shared computerized representation with open norms for interoperability (Smith \& Edgar, 2008 and Mccuen, 2008). Augmented Reality (AR) would give an environment a personal computer interface that would consistently coordinate into reality, so that the collaboration between users, different people or the environment itself would be, "in the most natural and intuitive way" (Riva, 2003). BIM-AR integration consists of using the building information models and presenting their virtual geometry or other associated data by augmenting them to the real environments to achieve effective and efficient visualization of the building components. BIM-AR can help in reduction of construction time, cost, and effort (Hou et al., 2013). Many models exist which can be used to implement AR solutions and the application of such BIM-based AR technologies in the construction industry has significantly expanded recently (Piroozfar et al., 2018). Since BIM-AR integrated technologies are still in the research phase, their full potential is not fully accomplished yet for fully functional real-world applications (Rankohi et al. 2013). The majority of current studies on BIM-AR integration have mainly focused on a specific application level; however, there is an insufficient amount of research conducted on issues related to successful implementation of BIM-AR integration (Wang et al., 2014). Moreover, there has been no study that investigated how the construction industry is accepting and adopting BIM-AR integration within their processes. There have been various studies that investigated BIM solely (Lee et al., 2017; Lee et al., 2015 and Son et al.,2014) or AR (tom Dieck et al., 2018 and Leue et al., 2014) acceptance and adoption individually but not their integrated BIMAR acceptance in the construction industry. Hence, this study aims to fill this knowledge gap by developing a Technology Acceptance Model (TAM) based on the integration of BIM-AR. TAM is an empirical model that can predict why and how IT users start and continue using modern technologies (Venkatesh and Bala, 2008). The study is significant as the developed TAM outcomes define the specific factors that affect BIM-AR Acceptance in developing countries. Identified factors such as perceived ease of use and perception of external control will be beneficial for construction organization as well as software developers while adopting or developing new BIMAR platforms.

\subsection{BUILDING INFORMATION MODELING AND AUGMENTED REALITY}

Building Information Modeling (BIM) is not only about 3D models or limited to visualizations but goes far beyond that. It includes the proper creation and utilization of digitized cost and time related data during the whole project, moreover, the maintenance of the deliverables lifecycle. BIM offers an improved collaboration environment between stakeholders in the design and the construction phase, as well as consistent coordination between different stakeholders (Chong et al., 2016). Augmented Reality (AR) as a part of the intelligently mixed reality, is "an evolution of traditional virtual reality environments" and is "the most ambitious expression of ambient intelligence" (Riva, 2003). AR has a compelling concept, which is making users satisfied with the digital content naturally, by effective integration of the two environments (Wang and Dunston, 2006). Bearing in mind that AR naturally includes the human sensations with both genuine and virtual data sources. It is also found that AR ought to be universal and cooperate with exact situating advances, for example, laser indicating. BIM gives moderately static and pre-characterized information and data. AR gives nearby growth and in addition to location detecting considering vision-based AR, can be a tracking apparatus too. AR, as a class of simple access interface, can change how site managers and other workers associate and retrieve advanced specialized data in BIM (Wang et al., 2012).

There have been several studies on BIM and AR integration in the construction literature. To improve tasks productivity through information handling, Chu et al. (2018) assessed the efficiency of BIM-AR integration and 
developed a BIM-AR cloud-based mobile application that helped in improving task efficiency by enhancing the process of data recovery during construction. A new methodology was proposed by Zaher et al. (2018) for monitoring the progress of construction work by developing an application for smartphones called "BIM-U" and an AR mobile channel called "BIM-Phase". The proposed methodology offers new opportunities to measure and monitor the progress of work utilizing BIM and AR. Due to the fast adoption and development of AR applications, there are many chances to integrate AR and enhance the traditional methods used in the various fields of the construction industry (Chi et al., 2013).

In an earlier study, Williams et al. (2015) developed an application called BIM2MAR and conducted a pilot study in a health-care facility management context and proposed a technique to give multiplex geometry through AR on a computationally simplified mobile system. In another BIM-AR integrated study, Kwon et al. (2014) established two types of deficiency management platforms including: (1) a platform that matches pictures for quality inspection without being in the actual job site; and (2) a mobile AR app that allows managers and workers to instantly recognize dimensions errors and exclusions on the work site. The two platforms are based on BIM, imagematching, and AR. The results support the effectiveness of the BIM-AR integrated system in instant exclusion and error recognition at real work sites. In another study, Chi et al. (2012) assessed an AR-enhanced teleoperated crane interface and discovered that the incorporation of AR in the construction machinery users interface has a positive effect on the performance of crane workers. In another BIM-AR integrated study, a monitoring tool for carbon footprint was proposed by Memarzadeh et al. (2012) which is based on producing AR-models in which the anticipated and emitted embodied carbon footprint of a project are mutually depicted in a standard BIM-based 3D environment. This BIM-AR integrated platform gives professionals an opportunity during coordination and submittal processes to ensure the punctual delivery of materials and to reduce carbon footprints of their projects. In another project, a new technology to prevent collisions between visual excavators and utilities was developed by Talmaki et al. (2010) through superimposing 3D information models of buried utilities over an excavator's workspace. The platform was utilizing geo-referenced AR to allow the operator and the spotter(s) to view the data and determine the type and location of utilities that exist in the area of the excavator. BIM-AR integration has become a common trend in the Architecture, Engineering, and Construction/ Facility Management (AEC/FM) literature which will maximize the potentials of BIM on site, and eventually becomes a digital toolkit for AEC/FM workers or professionals to easily access and interact with building information models on location-dependent contexts (Wang et al., 2013). It is also anticipated that such integration will ultimately be more utilized in the construction industry and improve safety, efficiency, and productivity of work (Chi et al., 2013).

\subsection{BIM-AR Adoption}

Many industry professionals in Architecture, Engineering, and Construction (AEC) specializations have been using $\mathrm{BIM}$ in construction and design. Whereas, there were not many endeavors investigating real-time correspondence and joining of BIM to the site, as well as the communication and integration of BIM within site. It is thought that AR can satisfy this vision successfully by placing BIM directly into the physical context of every activity for the construction industry. The integration of AR and BIM (BIM-AR) can provide a collaborative platform that will help in managing and exchanging all project related data. This collaborative platform can be supported and accessed on all mobile devices. Building Information models can be visualized on mobile phones and tablets via AR to help the construction stakeholders throughout the construction process to improve work quality (Wang et al., 2013). BIM-AR frameworks can recognize the interconnection, furthermore, the complication of the tasks derived from various parts that primarily concentrate on their individual tasks. Also, BIM-AR can improve making the interconnection between work tasks more explicit. Such integration makes the existing intricacy and interconnection to be managed better on site. As BIM-AR platforms are used, they can visually illustrate the correct and precise data from building information models to various users on the project. This way, all the workers and professionals on the site will be able to observe and see the progress of the work tasks at different stages, from start to finish of the project (Wang et al., 2014).

\subsection{Technology Acceptance Model}

Davis (1989) defined the Technology Acceptance Model (TAM) as a technique that is utilized for modeling user acceptance of information systems. TAM assumes that two convictions dictate an individual's behavioral aim to utilize a system. One is perceived usefulness, characterized as the degree to which a person trusts that utilizing this system will improve his or her employment execution. Secondly, the perceived ease of use, characterized by the degree to which a person trusts that utilizing this system will be free of exertion. It has been assumed that the 
effects of external factors (e.g., training, system characteristics and development procedures) on the expectation to use is intended by perceived usefulness and perceived ease of utilization. TAM 3 was developed by Venkatesh and Bala (2008) to complete the model integration with the antecedents of TAM. TAM 2 added the antecedents of perceived usefulness, while TAM 3 is expanded by the factors that forego perceived ease of use that have already been presented in Venkatesh and Davis (1996) and Venkatesh (2000). Specifically, adding on the anchoring (perceptions of external control, computer anxiety, computer playfulness, and computer self-efficacy) and modifying framing (objective usability and perceived enjoyment) decision making by humans as shown in Table 1 .

Table 1: Variables Definitions in TAM3 by Venkatesh and Bala (2008)

\begin{tabular}{|c|c|}
\hline Variable & Definition \\
\hline $\begin{array}{l}\text { Subjective Norm } \\
(\mathrm{SN})\end{array}$ & $\begin{array}{l}\text { "Person's perception that most people who are important to him think he should or should not perform the } \\
\text { behavior in question" }\end{array}$ \\
\hline $\begin{array}{l}\text { Voluntariness } \\
\text { (VOL) }\end{array}$ & "The extent to which potential adopters perceive the adoption decision to be non-mandatory". \\
\hline $\begin{array}{l}\text { Image } \\
\text { (IMG) }\end{array}$ & "The degree to which use of an innovation is perceived to enhance ones... status in one's social system." \\
\hline $\begin{array}{l}\text { Job Relevance } \\
\text { (REL) }\end{array}$ & "As users' understanding regarding the degree to which the chosen framework is viable to the users' job." \\
\hline $\begin{array}{l}\text { Output Quality } \\
\text { (OUT) }\end{array}$ & "Users will consider how good and the quality if the tasks performed by the framework." \\
\hline $\begin{array}{l}\text { Result Demonstrability } \\
\text { (RES) }\end{array}$ & "Tangibility of the results of using the innovation" \\
\hline $\begin{array}{l}\text { Computer Self-Efficacy } \\
\text { (CSE) }\end{array}$ & $\begin{array}{l}\text { "The degree to which an individual believes that he or she has the ability to perform a specific task/job using } \\
\text { the computer." }\end{array}$ \\
\hline $\begin{array}{l}\text { Perception of External } \\
\text { Control (PEC) }\end{array}$ & $\begin{array}{l}\text { "The degree to which an individual believes that organizational and technical resources exist to support the } \\
\text { use of the system. }\end{array}$ \\
\hline $\begin{array}{l}\text { Computer Anxiety } \\
\text { (CA) }\end{array}$ & $\begin{array}{l}\text { The degree of "an individual's apprehension, or even fear, when she/he is faced with the possibility of using } \\
\text { computers". }\end{array}$ \\
\hline $\begin{array}{l}\text { Computer Playfulness } \\
\text { (CPLAY) }\end{array}$ & "The degree of cognitive spontaneity in microcomputer interactions". \\
\hline $\begin{array}{l}\text { Perceived Enjoyment } \\
(\text { ENJ) }\end{array}$ & $\begin{array}{l}\text { The extent to which "the activity of using a specific system is perceived to be enjoyable in its own right, aside } \\
\text { from any performance consequences resulting from system use" }\end{array}$ \\
\hline
\end{tabular}

Venkatesh and Bala (2008) integrated TAM 2 (Venkatesh \& Davis, 2000) and the model of the determinants of perceived ease of use (Venkatesh, 2000) and created an integrated TAM 3. TAM 3 produced a fully complete network of the determinants of IT utilization and adoption (Figure 1).

Technology acceptance models (TAMs) were also used in a few studies within the construction domain. In a very recent study, Liu et al. (2018) developed an extended TAM to reflect the changes in attitude of construction practitioners that were modeled from a two-year longitudinal study which was conducted in parallel with the development of a smart system for prefabrication housing construction. The results of that research show that smart construction system developers should always improve the usefulness and user-friendliness of a system to facilitate its adoption. In another study, Niu et al. (2018) discussed that the initiatives of radio frequency identification (RFID) technologies and RFID-enabled management systems are yet to be fully accepted and adopted in practice. Moreover, they proposed an extended TAM as a guiding framework to give a better understanding of the practitioners' adoption and use behaviors. The research demonstrated that the construction practitioners' attitude is changing and heavily affected by the project managers who take the roles of system execution, or by peers who have harvested the benefits of such RFID-based systems. In another TAM study, Lee et al. (2017) developed and tested a conceptual model-based TAM that explained selection behavior in alternative dispute resolution methods in construction projects. In the same year, the Scanner Technology Acceptance Model (STAM) was proposed by Sepasgozaar et al. (2017) by using two major criteria; 'usefulness' and 'ease of use' for the acceptance of 3D scanners. The results demonstrate that STAM allows the suppliers of 3D scanners to expect the rate of diffusion and ease it for the users to decide on the proper technology they need for their project. 


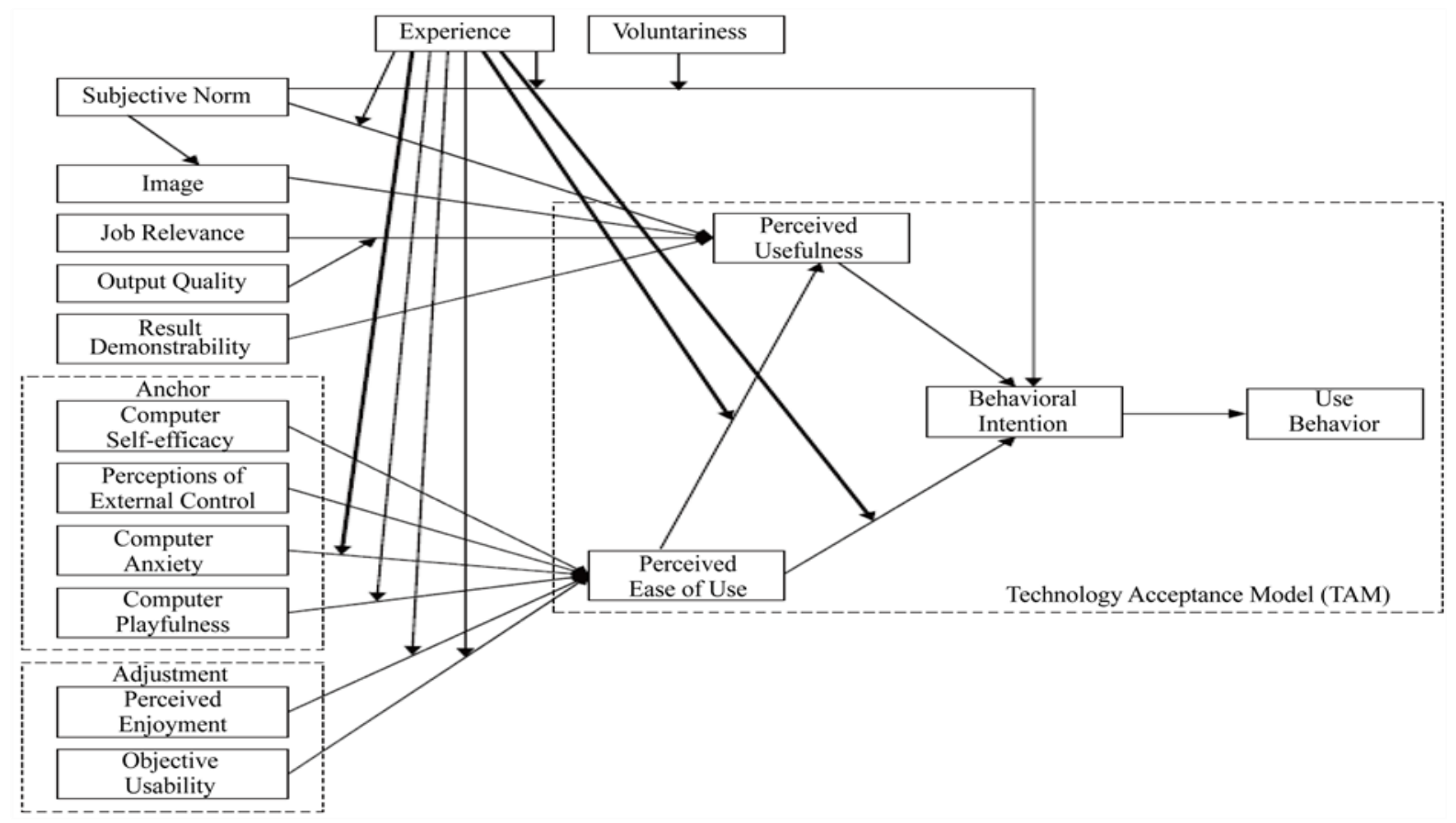

Figure 1: TAM 3 by Venkatesh and Bala (2008)

TAMs have also been used for studying building information modeling (BIM). In a very recent study on using technology acceptance models for BIM, Hong and Yu (2018) summarized the external variables that influences the use of BIM applications and explained the predicted impacts when the relationship among those external variables are assumed and verified by TAM. This study contributed to the development of mobile devices BIMbased user-oriented tools. In another study, Lee and Yu (2017) noticed that there is a high number of users who abandon BIM and therefore, developed a discriminant model of BIM acceptance readiness. The developed model increases awareness for evaluating and predicting BIM acceptance readiness. In another technology acceptance study of BIM, Guo et al. (2017) analyzed the degree of acceptance when using BIM in façade construction. Using such prior analysis, the acceptance level of BIM could be projected, and the factors affecting the user's negative attitude could be found. Thus, the builders could improve the factors and coordinate with users, making BIM technology be accepted in façade construction. Lee and Yu (2015) developed a TAM model to clarify the reasons for BIM adoption, how to enhance it and to realize the differences between the United States and Korea in the mechanism of BIM acceptance. The outcomes of the study showed that users in the US had higher adoption level for BIM than Korea and the two countries have different mechanisms for BIM acceptance. In another study, Son et al. (2014) found that there is a lack of realization of the expected benefits of BIM and examined the factors that can ease BIM adoption for architects. The outcomes of this technology acceptance study showed factors such as subjective norm, compatibility, and computer self-efficacy could influence the behavioral intentions for architects to BIM adoption. A few studies also used TAMs to study augmented reality (AR). Leue et al. (2014) developed an AR-TAM model and defined new external variables, such as perceived interest, costs, information quality, perceived pleasure, and personal innovativeness, that affect perceived ease of use and perceived usefulness in ARTAM. In another recent study, (Dieck and Jung, 2018) developed an AR-TAM model that proposed seven other external variables such as data quality, the cost of utilizing, recommendations, system quality, risk, innovativeness and facilitating conditions. All the previous studies have investigated the BIM and AR technology acceptance individually, and there has been no study that investigated how the construction industry is accepting and adopting BIM-AR integration within their processes. This study aims to fill this knowledge gap by developing a Technology Acceptance Model (TAM) based on the integration of BIM-AR. 


\subsection{METHODOLOGY}

The research instruments that have been chosen for the study is a literature review followed by a survey study to help in the data collection procedures and to achieve the objectives of this study. The TAM3 (Venkatesh and Bala, 2008) was adopted to create the questions within the survey. The analysis for the questionnaire is divided into two sections: Demographics and development of TAM3. For the first section of the questionnaire, the descriptive analysis will be carried out to identify the respondent's demographic characteristics. In the second section, respondents were asked a group of questions regarding each factor of the TAM3 (e.g., perceived usefulness perceived ease of use, computer self-efficacy). The final answer for each factor was measured based on a 7-point Likert scale (1: strongly disagree to 7: strongly agree). Finally, several statistical techniques such as reliability analysis, exploratory factor analysis (EFA), and regression analysis were used to develop and validate the TAM3. The Maximum likelihood (Tabachnick \& Fidell, 2007) was used for factor extraction in the factor analysis technique. This method attempts to analyze the maximum likelihood of sampling the spotted correlation matrix and is also used for estimating the loading of the factors for a population. Additionally, varimax method (as suggested by Tabachnick and Fidell (2007); Hair et al. (2006); and Pallant (2007)), was used as the most common orthogonal approach to minimize the numbers of variables which have high loading value on every single factor.

The study targeted construction professionals in four developing countries (Malaysia, Saudi Arabia, Egypt, and Turkey). Around $85.4 \%$ of the world's population lives in developing countries, and according to the united nation country classification report (2014), these four countries fall under the developing economics category which reflects their similar basic economic country conditions. Similar low-level of BIM and AR adoption in those developing countries, familiarity and previous experience of authors with the construction industry in those countries, as well as authors' accessibility to professionals in those countries were among the main reasons to choose those four countries for this step of our research. Google form was used to develop and administer the survey and facilitate data collection. The survey invitations were sent via emails and LinkedIn messages as a URL that allows the participants to access the survey questions directly. The survey lasted for around two months and then the data were downloaded and prepared for the analysis after the closing of the survey. From the 100 invitations sent for the survey, 61 respondents were received, and 58 respondents of them were valid for the data analysis. Many of the missing values were found in 3 out of 61 responses, which happened in a random pattern and the decision was to exclude these three responses to avoid any effects on the results. These 3 responses are less than 5\%; hence, the problem of missing data is not serious as per (Tabachnick and Fidell, 2007). Field (2009) recognized the acceptable loading level of the factors as 0.7 when the sample size is 50 or more. Additionally, Masrom (2007) in a similar study identified 0.6 and above as an acceptable value for the factor loading which has been adopted by this study. The respondent's demographic characteristics are illustrated in Table 2.

Table 2: Respondents Demography

\begin{tabular}{|c|c|c|c|c|c|}
\hline Country of Origin & $\#(\%)$ & Position & $\#(\%)$ & Years of Experience & $\#(\%)$ \\
\hline - Egypt & 25.8 & Civil Engineer & 51.7 & - Less Than 3 Years & 39.6 \\
\hline Malaysia & 29.4 & Architect & 15.6 & - 3-10 Years & 44.8 \\
\hline - $\quad$ Turkey & 24.2 & Project Manager & 10.3 & - More Than 10 Years & 15.6 \\
\hline - Saudi Arabia & 20.6 & - Other & 22.4 & & \\
\hline
\end{tabular}

To check the reliability, a Cronbach's Alpha was conducted to confirm that the results are relevant and acceptable for the Likert scale (Maidabino and Zainab, 2011). According to (Davis, 1989; Hinton et al., 2004; Field, 2009), Cronbach Alpha method is the most appropriate method for reliability testing of the TAM questionnaire. The standardized Cronbach's Alpha value is 0.959 . This value is very high and only 0.41 difference from 1 which proves that the questionnaire questions has a very high overall reliability (Davis,1989; Hinton, et al., 2004; Field, 2009). Bartlett's test of sphericity (Field, 2006) was conducted and the outcome supported the factorability and illustrated the existence of non-zero correlation and high level of homogeneity between the variables. Bartlett's test of sphericity showed an approximate Chi-square of 2072.35 with $630 \mathrm{df}$ and significance 0.000 . The KaiserMeyer-Olkin Measure of Sampling Adequacy KMO is 0.776 which exceeded the value of the cut-off point of 0.6 as recommended by Hair et al. (2006) and Field (2006). 


\subsection{RESULTS AND DISCUSSION}

\subsection{Exploratory Factor Analysis}

Exploratory Factor Analysis (EFA) is utilized when several factors affecting the variable need to be determined and to analyze which of the variables can match together (Yong \& Pearce, 2013). The EFA produced 10 factors solution because only 10 factors are retained as this study considers 0.6 and higher according to Hair et al. (2006) as an acceptable level of variance in the factors loading, and the extracted factors account for $77.93 \%$ of the total variance. All factors with loadings higher than 0.6 are reported in Table 3 . These factors are perceived ease of use, perceived usefulness, perceived enjoyment, image, computer anxiety, job relevance, voluntariness, behavioral intention, result demonstrability and perception of external control. Factors such as computer playfulness, subjective norm, experience, and output quality were excluded due to their low loading (less than 0.6).

Table 3: Rotated Factor Matrix of TAM with the retained factors

\begin{tabular}{|c|c|}
\hline Factors and Variables & Loadings \\
\hline \multicolumn{2}{|l|}{ Perceived Ease of Use (PEOU) } \\
\hline - The system is easy to use & 0.85 \\
\hline - $\quad$ Easy to control & 0.82 \\
\hline - Won't require mental effort & 0.73 \\
\hline \multicolumn{2}{|l|}{ Perceived Enjoyment $($ ENJ $)$} \\
\hline • Using the system would be fun & 0.79 \\
\hline - The process of using the system would be pleasant & 0.78 \\
\hline • The system would be enjoyable & 0.74 \\
\hline \multicolumn{2}{|l|}{ Image (IMG) } \\
\hline - $\quad$ System users have more prestige & 0.92 \\
\hline - $\quad$ Having the system would be a status symbol & 0.90 \\
\hline - $\quad$ System users would have a higher profile & 0.84 \\
\hline \multicolumn{2}{|l|}{ Behavioral Intention $(B I)$} \\
\hline - The user would use the system if he has access & 0.75 \\
\hline \multicolumn{2}{|l|}{ Perceived Usefulness $(P U)$} \\
\hline • The system would increase the productivity & 0.72 \\
\hline - $\quad$ The system would improve my job performance & 0.71 \\
\hline - The system would enhance effectiveness in the job & 0.71 \\
\hline \multicolumn{2}{|l|}{ Computer Anxiety $(\mathrm{CANX})$} \\
\hline - Computers make me feel uneasy & 0.94 \\
\hline - Computers make me feel uncomfortable & 0.91 \\
\hline \multicolumn{2}{|l|}{ Job Relevance $($ REL) } \\
\hline • The usage of the system would be important & 0.82 \\
\hline - The usage of the system would be relevant to my job & 0.76 \\
\hline \multicolumn{2}{|l|}{ Voluntariness (VOL) } \\
\hline - The system is not compulsory in my job & 0.81 \\
\hline - I wasn't told to use the system & 0.75 \\
\hline \multicolumn{2}{|l|}{ Result Demonstrability (RES) } \\
\hline - Using the system can facilitate communications to others & 0.80 \\
\hline - $\quad$ System results would be apparent to me & 0.63 \\
\hline \multicolumn{2}{|l|}{ Perception of External Control (PEC) } \\
\hline - I would have control over the system & 0.78 \\
\hline
\end{tabular}

Interestingly, the most significant factors that affect users' image are the user's prestige (Loading: 0.92) and the status symbol (0.90) when the organization starts utilizing the BIM-AR. This indicates the prestige the users may gain when they utilize modern technology in their organizations. On the other hand, the most significant factors that influence anxiety from computers, are that computers make them feel uneasy (0.94) or uncomfortable (0.91) and this might be the case for older users in developing countries. A significant factor that influences the enjoyment is that users expect using the system to be fun (.79) and enjoyable (0.74) as technology is always perceived as a 
fun activity. Additionally, users would utilize the system more if they were not told to do so (0.75) and even if it is not compulsory by their company (0.81), which is an excellent indication for the user's readiness to accept and utilize BIM-AR voluntarily. Users perceive the usefulness of the system if it would increase their productivity (0.72), enhance their job performance (0.71) and effectiveness at their jobs (0.71). All other factors have loadings with a value over 0.6 which is considered effective which means that each factor represents their variable efficiently as recommended by Hair et al. (2006).

\subsection{Regression Analysis}

Regression analysis includes the study of the correlation between the dependent variable with one or more independent variables. In this study, a regression analysis was used to investigate the most effective factors of users' approach to accepting BIM-AR integration in the construction industry and also to validate the relations in the developed TAM3.

Table 4 shows the regression results of the TAM. The two external factors are shown to be insignificant. (1) Computer anxiety has an insignificant effect on the perceived ease of use which indicates the increased awareness in the developing countries related to computers and smartphones. (2) User image is shown to have an insignificant effect on the perceived usefulness as users identified the system usefulness as related to enhancement in the performance and not related to the prestige they have when using the system. On the other hand, the perception of external control is the most significant predictor of perceived usefulness and behavioral intention. These outcomes show that users' control over the system and given the resources and knowledge about the BIM-AR will increase their perceived usefulness of the system which ultimately will lead to a significant effect on their intention to utilize the system.

Table 4: Regression Results of TAM3

\begin{tabular}{|l|l|c|c|c|}
\hline \multirow{2}{*}{ Dependent Variable } & Independent Variable & $\begin{array}{c}\text { Standardized } \\
\text { Coefficients ( } \boldsymbol{\beta})\end{array}$ & Significance P & $\begin{array}{c}\text { Significance } \\
\text { level (P value) }\end{array}$ \\
\hline \multirow{4}{*}{ Behavioral Intention (BI) } & Perceived Ease of Use (PEOU) & 0.434 & 0.000 & $\mathrm{p}<0.05$ \\
\cline { 2 - 5 } & Perceived Usefulness (PU) & 0.473 & 0.000 & $\mathrm{p}<0.05$ \\
\cline { 2 - 5 } & Image (IMG) & 0.405 & 0.002 & $\mathrm{p}<0.05$ \\
\hline Perceived Usefulness (PU) & Perceived Ease of Use (PEOU) & 0.506 & 0.000 & $\mathrm{p}<0.05$ \\
\hline \multirow{4}{*}{ Perceived Ease of Use (PEOU) } & Voluntariness (VOL) & 0.291 & 0.023 & $\mathrm{p}<0.05$ \\
\cline { 2 - 5 } & Computer Anxiety (CANX) & 0.147 & 0.24 & Not significant \\
\cline { 2 - 5 } & Perceived Enjoyment (ENJ) & 0.278 & 0.034 & $\mathrm{p}<0.05$ \\
\hline \multirow{3}{*}{ Perceived Usefulness (PU) } & Image (IMG) & 0.01 & 0.45 & Not Significant \\
\cline { 2 - 5 } & Job Relevance (REL) & 0.274 & 0.033 & $\mathrm{p}<0.05$ \\
\cline { 2 - 5 } & Perception of External Control (PEC) & 0.755 & 0.000 & $\mathrm{p}<0.05$ \\
\cline { 2 - 5 } & Result Demonstrability (RES) & 0.293 & 0.036 & $\mathrm{p}<0.05$ \\
\hline
\end{tabular}

As shown in Figure 2, perceived ease of use has a strong influence on the perceived usefulness which means if users found the system easy to use, they will have higher confidence in the system usefulness. Perceived ease of use and perceived usefulness were found to have a strong influence on the behavioral intention to use BIM-AR. This result supports the research findings of the original TAM model that were utilized by Venkatesh and Bala (2008) to develop TAM3 by confirming that user's perceived ease of use and perceived usefulness have a direct impact on the determinants of the behavioral intention and perceived ease of use and perceived usefulness have a direct influence on the user's intention to accept and use BIM-AR.

The perceived usefulness of BIM-AR appears to have a bit higher effect on the intention to use the system compared to the perceived ease of use, as users prefer to use BIM-AR because it is useful to them even though it may need an effort to use. Additionally, enjoyment is found to have a direct impact on the ease of use. This relationship shows that the more enjoyable BIM-AR is perceived to the users, the more perception of easiness they have to the system, and ultimately the more useful they will perceive the system, they will be more motivated to use the system.

Job relevance has a direct influence on perceived usefulness, which means if the users found the BIM-AR relevant to their job, it will increase their perception of its usefulness and their motivation to use the system. That might depend on the user's awareness of the technology; as if their awareness is low, they might perceive the technology 
as non-relevant to their job and accordingly they would not consider it useful or get the intention to use it. Also, if using BIM-AR would improve the collaboration between different stakeholders (result demonstrability), this would have a direct influence on the perception of the system usefulness and the intention to use it. This outcome illustrates how critical industry stakeholders perceive collaboration.

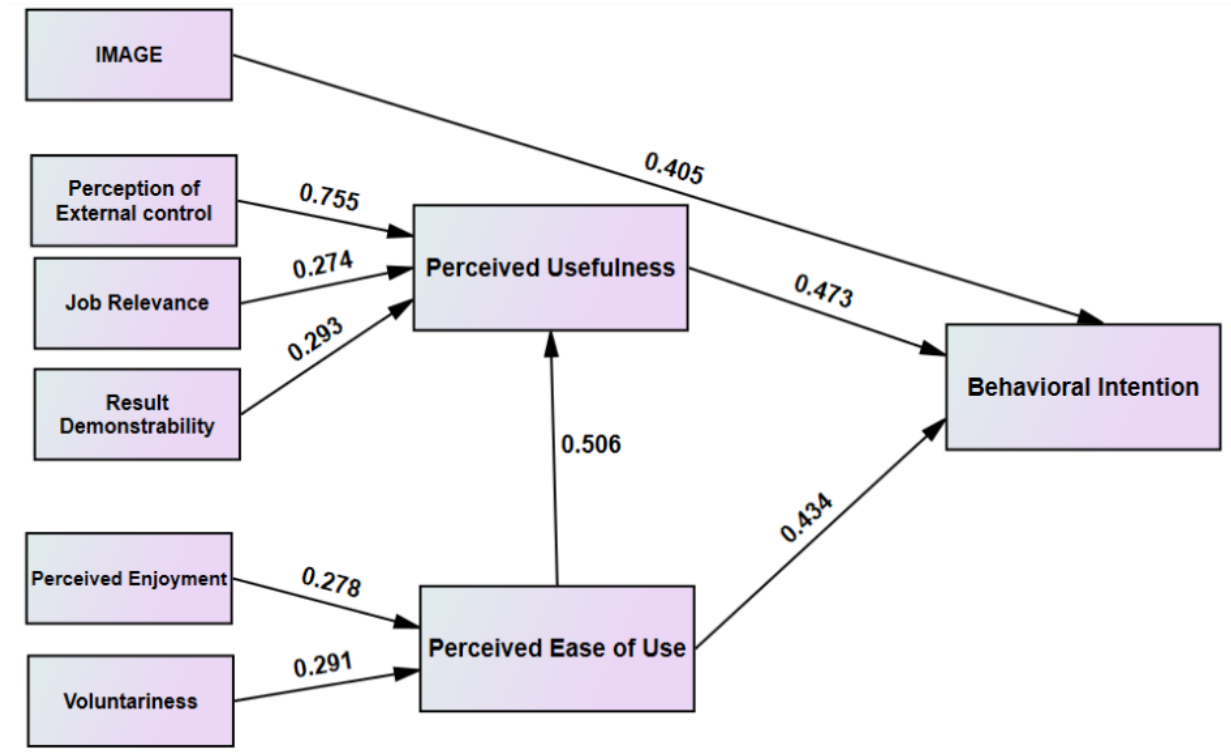

Figure 2: Developed TAM for BIM-AR Integration with Regressions Analysis

Users' image and prestige for using the BIM-AR are found to have a significant impact on the intention to use it, which is considered the unexpected result as in the TAM 3 developed by Venkatesh and Bala (2008). Users' image influences on the perceived usefulness of BIM-AR. However, the image did not have a significant impact on the intention to use the system which indicates that the users care about their image and prestige and may use BIMAR because of the prestige they get while utilizing it. This result shows how significant the prestige is in using these technologies and illustrates its impact on the actual usage.

Moreover, the perception of external control was found to have a very strong influence on perceived usefulness and not perceived ease of use unlike in the original TAM 3 model, as users perceive that their control over the system will have higher influence on the usefulness of the system more than the easiness of use. This indicates that control is a crucial factor when determining system usefulness. Voluntariness was found to have a direct influence on perceived ease of use and not the perceived usefulness, unlike the TAM3 by Venkatesh and Bala (2008), which indicates that when users use the system voluntarily they find it easier to use more than if they were told to use it. This shows the user's readiness to utilize BIM-AR and it has no influence on their perception of how useful the system is.

\subsection{Study Limitations}

There are limitations related to this study that need to be mentioned. The sample size is small, and some caution is necessary for generalizing the findings of this study. According to Hatcher (2005), for TAM questionnaire, the recommended sample size should be five times the number of variables. This study had 50 variables, and effective sample size should have been 250. In a few years and with further implementation of BIM-AR, a similar study should be conducted with larger sample size. The other limitation of the study is the scope of it which was limited to a few developing countries. A similar study should also be conducted with the scope of developed countries with which to compare the findings of this study. There is a good potential that the outcomes of such study targeting developed countries might be different from the developing ones due to the broad integration of IT solutions in the construction industry in developed countries, unlike the developing ones. Finally, the results of this study could have been analyzed and validated using a different approach than using factor analysis and regression analysis. Structural Equation Modeling (SEM) can be used to analyze the results of this study. SEM uses Confirmatory Factor Analysis (CFA) which is a statistical method that detects the structure of factors by taking into account their components (Suhr, 2006). 


\subsection{CONCLUSION}

Perception of external control and perceived ease of use are the most significant predictors of the user's perceived usefulness for BIM-AR platform, which means users would perceive the system as useful and have confidence in if they believe that they have control over it and access to the required resources. Perceived ease of use and perceived usefulness are the most influential factors on the user's behavioral intentions to use the BIM-AR which also supports the TAM results. The three variables of image, perception of external control, and voluntariness were found to have a new relationship as well as an effective influence on behavioral intention, perceived usefulness, and perceived ease of use respectively. These results are different than what TAM 3 was illustrating and is an indicator of this study's unique results. This study generated a new validated TAM model for the BIM-AR integration which can evaluate the user's acceptance of these technologies in the construction industry within the scope of developing countries. However, some caution is necessary for generalizing the findings of these results due to the limitations of this study. The developed TAM3 model can also be utilized by software developers or other organizations to evaluate the acceptance of new BIM-AR systems. Software developers can consider important factors identified through this study, such as ease of use and the perceived enjoyment of the software, to create BIM-AR platforms that have a higher possibility to be used and accepted by the users. For organizations, providing training for the stakeholders before using the system appears to be significantly effective as users perception of external control and ease of use are among vital factors for accepting the BIM-AR.

\section{REFERENCES}

Chi, H. L., Chen, Y. C., Kang, S. C., and Hsieh, S. H. (2012). Development of user interface for tele-operated cranes. Advanced Engineering Informatics, 26(3), 641-652.

Chi, H. L., Kang, S. C., and Wang, X. (2013). Research trends and opportunities of augmented reality applications in architecture, engineering, and construction. Automation in construction, 33, 116-122.

Chong, H. Y., et al. (2016). "Comparative analysis on the adoption and use of BIM in road infrastructure projects." Journal of Management in Engineering 32(6): 05016021.

Chu, M., Matthews, J., and Love, P. E. (2018). Integrating mobile building information modelling and augmented reality systems: an experimental study. Automation in Construction, 85, 305-316.

Davis, F. D. (1989). "Perceived usefulness, perceived ease of use, and user acceptance of information technology." MIS quarterly: 319-340.

Davis, F. D. (1993). "User acceptance of information technology: system characteristics, user perceptions and behavioral impacts." International journal of man-machine studies 38(3): 475-487.

Davis, F. D., et al. (1989). "User acceptance of computer technology: a comparison of two theoretical models." Management science 35(8): 982-1003.

Eastman, C. M., et al. (2011). BIM handbook: A guide to building information modeling for owners, managers, designers, engineers and contractors, John Wiley \& Sons.

Field, A. (2009). Discovering statistics using SPSS, Sage publications.

Field, A. 2006. Discovering Statistics Using SPSS. 2nd ed. London. Thousand Oaks. New Delhi: Sage Publication.

Fishbein, M. and I. Ajzen (1975). Belief, attitude, intention, and behavior: An introduction to theory and research.

Froese, T. M. (2005). Impact of emerging information technology on information management. Computing in Civil Engineering (2005): 1-10.

Guo, J., Yang, J., Peng, S., and Mao, C. (2017) Exploring effective BIM workflow among practitioners by Technology acceptance model: a case study on the construction of facade.

HAIR, J., BLACK, B., BABIN, B., RALPH, A. \& RONALD, T. 2006. Multivariate Data Analysis. 6th ed. London: Prentice-Hall.

Hatcher, L. (2005). A step-by-step approach to using the SAS system for factor analysis and structural equation modeling, SAS Institute Cary, NC.

Hinton, P. R., et al. (2004). SPSS explained, Routledge. 
Hong, S. H., \& Yu, J. H. (2018, September). Identification of external variables for the Technology Acceptance Model (TAM) in the assessment of BIM application for mobile devices. In IOP Conference Series: Materials Science and Engineering Vol. 401, No. 1, 012027. IOP Publishing.

Hou, L., et al. (2013). "Using augmented reality to facilitate piping assembly: an experiment-based evaluation." Journal of Computing in Civil Engineering 29(1): 05014007.

Kwon, O. S., Park, C. S., and Lim, C. R. (2014). A defect management system for reinforced concrete work utilizing BIM, image-matching and augmented reality. Automation in construction, 46, 74-81.

Lee, C. K., Yiu, T. W., and Cheung, S. O. (2017). Understanding Intention to Use Alternative Dispute Resolution in Construction Projects: Framework Based on Technology Acceptance Model. Journal of Legal Affairs and Dispute Resolution in Engineering and Construction, 10(1), 04517021.

Lee, S., and Yu, J. (2015). Comparative study of BIM acceptance between Korea and the United States. Journal of Construction Engineering and Management, 142(3), 05015016.

Lee, S., and Yu, J. (2015). Comparative study of BIM acceptance between Korea and the United States. Journal of Construction Engineering and Management, 142(3), 05015016.

Lee, S., and Yu, J. (2017). Discriminant model of BIM acceptance readiness in a construction organization. KSCE Journal of Civil Engineering, 21(3), 555-564.

Lee, S., and Yu, J. (2017). Discriminant model of BIM acceptance readiness in a construction organization. KSCE Journal of Civil Engineering, 21(3), 555-564.

Leue, M., and Jung, T. H. (2014). A theoretical model of augmented reality acceptance. E-review of Tourism Research, 5 .

Liu, D., Lu, W., and Niu, Y. (2018). Extended Technology-Acceptance Model to Make Smart Construction Systems Successful. Journal of Construction Engineering and Management, 144(6), 04018035.

Maidabino, A. and A. Zainab (2013). "Collection security management at university libraries: assessment of its implementation status." arXiv preprint arXiv:1301.5385.

Mansor, S. A. (2010). "The 7th Malaysia construction sector review and outlook seminar." The Construction Sector at the Onset of the 10th Malaysia Plan. Kuala Lumpur.

Masrom, M. (2007). "Technology acceptance model and e-learning." Technology 21(24): 81.

McCuen, T. L. and M. MSCS (2008). Building information modeling and the interactive capability maturity model. Associated Schools of Construction International Proceedings of the 44th Annual Conference, Auburn, Alabama.

Niu, Y. H., Lu, W. S., and Liu, D. D. (2018). RFID-Enabled Management System Adoption and Use in Construction: Passing Through the Labyrinth with an Improved Technology Acceptance Model. In Proceedings of the 21st International Symposium on Advancement of Construction Management and Real Estate 1251-1258. Springer, Singapore.

Piroozfar, A., Farr, E. R., Boseley, S., Essa, A., and Jin, R. (2018). The application of Augmented Reality (AR) in the Architecture Engineering and Construction (AEC) industry.

Rankohi, S., and Waugh, L. (2013). Review and analysis of augmented reality literature for construction industry. Visualization in Engineering, 1(1), 9.

Riva, G. (2003). "Ambient intelligence in health care." CyberPsychology \& Behavior 6(3): 295-300.

Sabongi, F. J. and M. Arch (2009). The Integration of BIM in the Undergraduate Curriculum: an analysis of undergraduate courses. Proceedings of the 45th ASC Annual Conference, The Associated Schools of Construction.

Sepasgozaar, S. M., Shirowzhan, S., and Wang, C. C. (2017). A Scanner Technology Acceptance Model for Construction Projects. Procedia engineering, 180, 1237-1246.

Smith, D. and A. Edgar (2008). Building Information Modeling. Retrieved 12th August, 2010.

Son, H., Lee, S., Hwang, N., and Kim, C. (2014). The adoption of building information modeling in the design 
organization: An empirical study of architects in Korean design firms. In ISARC. Proceedings of the International Symposium on Automation and Robotics in Construction (Vol. 31, p. 1).

Suhr, D. D. (2006). Exploratory or confirmatory factor analysis?, SAS Institute Cary.

Tabachnick, B. G. and L. S. Fidell (2007). Using multivariate statistics, Allyn \& Bacon/Pearson Education.

Talmaki, S. A., Dong, S., and Kamat, V. R. (2010). Geospatial databases and augmented reality visualization for improving safety in urban excavation operations. In Construction Research Congress 2010: Innovation for Reshaping Construction Practice 91-101.

tom Dieck, M. C., and Jung, T. (2018). A theoretical model of mobile augmented reality acceptance in urban heritage tourism. Current Issues in Tourism, 21(2), 154-174.

United Nations (2014), "Country Classification: Data Sources, Country Classifications, and Aggregation Method.'http://www.un.org/en/development/desa/policy/wesp/wesp_current/2014wesp_country_classific ation.pdf (accessed 7 February 2019).

Venkatesh, V. (2000). "Determinants of perceived ease of use: Integrating control, intrinsic motivation, and emotion into the technology acceptance model." Information systems research 11(4): 342-365.

Venkatesh, V. and F. D. Davis (1996). "A model of the antecedents of perceived ease of use: Development and test." Decision sciences 27(3): 451-481.

Venkatesh, V. and H. Bala (2008). "Technology acceptance model 3 and a research agenda on interventions." Decision sciences 39(2): 273-315.

Wang, X. and P. S. Dunston (2007). "Design, strategies, and issues towards an augmented reality-based construction training platform." Journal of Information Technology in Construction (ITcon) 12(25): 363380.

Wang, X., Kim, M. J., Love, P. E., and Kang, S. C. (2013). Augmented Reality in built environment: Classification and implications for future research. Automation in construction, 32, 1-13.

Wang, X., Love, P. E. D. and Davis, P. R. (2012). BIM+ AR: a framework of bringing BIM to construction site. Construction Research Congress 2012: Construction Challenges in a Flat World.

Wang, X., Truijens, M., Hou, L. and Wang, Y. (2013). Application of collaborative mobile system in ar-based visualization, data storage, and manipulation. International Conference on Cooperative Design, Visualization and Engineering, Springer.

Wang, X., Truijens, M., Hou, L., Wang, Y. and Zhou, Y.(2014). "Integrating Augmented Reality with Building Information Modeling: Onsite construction process controlling for liquefied natural gas industry." Automation in Construction 40: 96-105.

Williams, G., Gheisari, M., Chen, P. J., and Irizarry, J. (2014). BIM2MAR: an efficient BIM translation to mobile augmented reality applications. Journal of Management in Engineering, 31(1), A4014009.

Yong, A. G. and S. Pearce (2013). "A beginner's guide to factor analysis: Focusing on exploratory factor analysis." Tutorials in quantitative methods for psychology 9(2): 79-94.

Zaher, M., Greenwood, D., and Marzouk, M. (2018). Mobile augmented reality applications for construction projects. Construction Innovation, 18(2), 152-166. 